\title{
Urbanization suitability maps: a dynamic spatial decision support system for sustainable land use
}

\author{
M. Cerreta and P. De Toro \\ University of Naples "Federico II", Naples, Italy \\ Correspondence to: M. Cerreta (cerreta@unina.it) \\ Received: 20 September 2012 - Published in Earth Syst. Dynam. Discuss.: 4 October 2012 \\ Revised: 13 November 2012 - Accepted: 14 November 2012 - Published: 20 November 2012
}

\begin{abstract}
Recent developments in land consumption assessment identify the need to implement integrated evaluation approaches, with particular attention to the development of multidimensional tools for guiding and managing sustainable land use. Land use policy decisions are implemented mostly through spatial planning and its related zoning. This involves trade-offs between many sectorial interests and conflicting challenges seeking win-win solutions. In order to identify a decision-making process for land use allocation, this paper proposes a methodological approach for developing a Dynamic Spatial Decision Support System (DSDSS), denominated Integrated Spatial Assessment (ISA), supported by Geographical Information Systems (GIS) combined with the Analytic Hierarchy Process (AHP). Through empirical investigation in an operative case study, an integrated evaluation approach implemented in a DSDSS helps produce "urbanization suitability maps" in which spatial analysis combined with multi-criteria evaluation methods proved to be useful for both facing the main issues relating to land consumption as well as minimizing environmental impacts of spatial planning.
\end{abstract}

\section{Introduction}

Urban development and land consumption are two of the major conflicting forces driving changes in land use and land cover, characterizing the growth of cities and their sustainability. The problematic expansion of urbanization at the expense of open space and natural resources has sparked intense interest and conflicting debate over the critical aspects and potentials of territorial development (Weber et al., 2006;
Potschin, 2009; Walter and Stützel, 2009; Schetke et al., 2012; Terzi and Bölen, 2012).

If we look at Europe, it is evident that it is one of the most urbanized continents in the world (EEA, 2009). Cities are economic engines but they are also contexts for the environmental, cultural and social quality of life. However, the open conflict between economic growth and cultural, social and environmental development determines a number of different consequences for urban and regional development, such as urban sprawl and the diffusion of low-density settlements, with increasing pressure on greenfield land.

Ongoing urbanization and territorial transformation are perceived as some of the main challenges facing the definition of development strategies. At the same time, a general lack of consideration of the value of the land implies many regional criticalities relating to the degradation of agricultural land, urban dispersion, spatial and ecological fragmentation, etc., imposing the need to consider land consumption as an essential factor that must be supported by suitable methods for its measurement and assessment on all levels of urban and regional planning (Hasse and Lathrop, 2003; De La Rosa, 2005; Tsai, 2005; Huang et al., 2007; Peng et al., 2007; Torrens, 2008; Jones et al., 2009; Winter and Lobley, 2009; Gerundo and Grimaldi, 2011).

Soil is an extremely complex, variable living resource which performs many vital functions. It is the interface between the earth, the air and the water and it plays a role as a habitat and gene pool. It serves as a platform for human activities and provides raw materials. These functions are worthy of protection because of their socio-economic and environmental importance. Today soil degradation (erosion, loss of organic matter, compaction, salinization, landslides, contamination, sealing, etc.) is accelerating with negative effects 
on human health, natural ecosystems and climate change, as well as on the economy (EC, 2012). Indeed, soil degradation is exacerbated by human activities, such as some agricultural and forestry practices, industrial uses, tourism and urban development (COM, 2006a). In particular, land take, also referred to as land consumption, describes the increase in urban areas over time. This process includes the development of scattered settlements in rural areas, the expansion of urban areas around an urban nucleus (including urban sprawl), and the conversion of land within an urban area (densification). Depending on local circumstances, a greater or smaller amount of land take will result in actual soil sealing (EC, 2012).

At present, approximately $75 \%$ of the European population currently lives in urban areas. By 2020 it is estimated that this will increase to $80 \%$ (EEA, 2010a). But since the mid-1950s, the total area of cities in the EU has increased by $78 \%$, whereas the population has grown by only $33 \%$ (EEA, 2006). Today, the European areas classified as "periurban" have the same amount of built-upon land as urban areas, but are only half as densely populated (Piorr et al., 2011). According to data published by the European Environment Agency in the context of the Corine Land Cover for the years 1990, 2000 and 2006 (CLC, 2012), it has been estimated that detected land take between 1990 and 2000 was approximately $1000 \mathrm{~km}^{2}$ per year in the EU. Urban areas increased by nearly $6 \%$ (Prokop et al., 2011). From 2000 to 2006, the rate of land take decreased slightly to $920 \mathrm{~km}^{2}$ per year, while the total urban area increased by a further $3 \%$. This corresponds to an increase of almost $9 \%$ between 1990 and 2006 (from 176200 to $191200 \mathrm{~km}^{2}$ ). But, in the same period, population increased by only $5 \%$, although there is a wide difference in population growth across Europe and within regions (EC, 2012). The result is a much more complex and confusing growth of urbanized areas, further accentuated by the progressive and concomitant expansion of the long-distance mobility basins threatening to irreversibly alter the polycentric character of many European urban regions.

Urban sprawl, exploded city, urban nebula, urbanized countryside, "peripheralization" of the countryside etc., are just some of the definitions that identify the most significant regional phenomena. They evoke the idea of a more indefinite and unstructured space, with no effective system of planning. In general, urban areas have expanded even further at the expense of all other land-cover categories, with the exception of forests and water bodies. Urbanization and expanding transport networks are fragmenting habitats and affect ecosystem services, playing a crucial role because they influence water, and nutrient and carbon cycles as well. Indeed, organic soil matter is a major terrestrial sink of carbon and so it is important for mitigating climate change. Peat soils represent the highest concentration of organic matter in all soils, followed by extensively managed grassland and forest. Carbon losses through the soil thus occur when these systems are transformed or converted to other uses. Loss of these habitats is also associated with decreased water retention capacity, increased flooding, erosion risks and reduced desirability. While the slight increase in forests is a positive development, the decline in natural and semi-natural habitats (including grassland, bogs, heaths and fens) is a major cause for concern (EEA, 2010a,b,c). The long-term sustainability of Europe's land use was a focus of the European Spatial Development Perspective (EC, 1999). Its vision was carried forward and supplemented with new priorities contained in the EU Territorial Agenda and the Action Programme for its implementation (COPTA, 2007) which defined an intergovernmental programme up to 2011. Indeed, in Europe there are a variety of initiatives that have been developed over the past years aiming at the collection of soil information. These initiatives were developed over a time frame of several decades and were coordinated by subjects on different levels: Global (FAO, UNEP, etc.), European (EU, ECE/ICP Forest, FOREGS), National, Regional and Local. Different approaches are required for each of the recognized threats to European soils. While some of the threats may require systematic monitoring, other threats need a more focused approach that takes into account the fact that they do not occur everywhere in Europe. Indeed, stratification of the European soils according to each of the single threats would allow the development of targeted monitoring approaches (Van-Camp et al., 2004).

Different EU policies (for instance regarding water, waste, chemicals, industrial pollution prevention, nature protection, pesticides, agriculture) contribute to soil protection. The Commission adopted a Soil Thematic Strategy (COM, 2006a) and a proposal for a Soil Framework Directive (COM, 2006b) with the goal of protecting soils across the EU and defining how to use them in a sustainable way on the regional and local levels. About five years after the adoption of the Soil Thematic Strategy, the European Commission published a policy report on the implementation of the Strategy and ongoing activities (COM, 2012). The report provides an overview of the actions undertaken by the European Commission to implement the four pillars of the Strategy, namely awareness raising, research, integration, and legislation in order to protect European soils and ensure their sustainable use. According to this perspective, the European Commission drafted the Guidelines on best practice to limit, mitigate or compensate soil sealing (EC, 2012) in order to identify the impacts of soil sealing, to recognize some common aspects, to limit the soil sealing phenomenon and to mitigate and compensate for its effects. The Commission Staff Working Document describes approaches based on three main strategies:

1. limiting, which means preventing the conversion of green areas and the subsequent sealing of (part of) their surface. Re-use of already built-up areas, e.g. brownfield sites, can also be included in this concept. Targets have been used as tools for monitoring as well as 
spurring progress; creating incentives to rent unoccupied dwellings has also helped in limiting soil sealing;

2. mitigating, which means identifying some appropriate mitigation measures in order to maintain some of the soil functions and reduce any significant direct or indirect negative effects on the environment and human well-being. For example, these include using permeable materials instead of cement or asphalt, supporting green infrastructure, and making wider use of natural water harvesting systems;

3. compensating, which means selecting some compensation measures, considering, however, that sealing cannot be compensated for precisely. Indeed, the purpose is to sustain or restore the overall capacity of soils in a certain area and to fulfill (most of) their functions.

In particular, attention to green infrastructure is considered a way to ensure that Europe's limited land can be utilized as areas providing multiple functions for nature and society. Green infrastructure is an important element in the EU's biodiversity and nature policy that will contribute greatly to efforts in reaching the agreed-upon EU biodiversity targets, covered under the EU 2020 biodiversity strategy. It is considered an essential tool for mitigating fragmentation and unsustainable land use both within and outside Natura 2000 areas, and for providing the multiple benefits of maintaining and restoring ecosystems and their services (EEA, 2011).

The ongoing urbanization and conversion of landscape and territory is perceived as one of the main challenges; Roadmap to a Resource Efficient Europe (COM, 2011) should be implemented by 2020 , recognizing furthermore that land take is generally connected with soil sealing. The Roadmap proposes that EU policies take into account their direct and indirect impact on land use in the EU and globally; the rate of land take must be on track with the goal of achieving zero net land take by 2050 . In this perspective, spatial planning can play an important role in achieving more sustainable land use by taking into account the quality and features of different land areas and soil functions in relation to competing objectives and interests, with a view to the long term.

Through the empirical investigation in an operative case study conducted during the Strategic Environmental Assessment (SEA) process for the City Plan of the municipality of Montecorvino Rovella in the Province of Salerno in Southern Italy, an integrated evaluative approach - denominated Integrated Spatial Assessment (ISA) - was implemented in a Dynamic Spatial Decision Support System (DSDSS). This approach, supported by a Geographical Information Systems (GIS) combined with an Analytic Hierarchy Process (AHP), helps draft urbanization suitability maps, where spatial analysis together with multi-criteria methods help identify the main issues relating to land consumption, and also minimize the environmental impacts of City Plan strategies.
The article is structured as follows: Sect. 2 provides a description of some integrated approaches and tools that can support a Strategic Environmental Assessment (SEA) process, emphasizing the need to integrate the SEA decisionmaking process with a multi-methodological framework through the proposal of the Integrated Spatial Assessment (ISA). The SEA process and its application are analyzed in Sect. 3, considering the case study of Montecorvino Rovella (Italy), with particular focus on urbanization suitability maps that can improve the planning process. Land consumption and some related indexes and indicators are analyzed in order to minimize the negative effects of urbanization. Finally, Sect. 4 provides some conclusions and proposals for future applications and improvements according to a multidimensional perspective open to interaction and synergy between methodological approaches and evaluative tools.

\section{Integrated approaches and tools}

Policy and planning decisions shaping land use involve a variety of trade-offs between many sectorial interests (industry, transport, energy, mining, agriculture and forestry, etc.). These trade-offs can be faced through integrated programmes and approaches for land use, spatial planning, and land management practices that include the implementation of renewable energy targets, forest and agricultural land use, green infrastructure, land re-use and more general land resource management (EEA, 2010c).

According to this view, Strategic Environmental Assessment (SEA) and Environmental Impact Assessment (EIA) are important tools for evaluating plans, programmes and projects impacting land resources. Indeed, their implementation has shown that they can help improve the consideration of environmental aspects, contributing to more systematic and transparent planning and increasing participation and consultation of stakeholders (public, NGOs, associations, different authorities at all levels, etc.). However, the effectiveness of the tools, in particular SEA, is strictly linked to the approach regarding screening criteria, identification of alternatives, and improved data (EC, 2009). The European Commission has noted (COM, 2009) that the effect of the SEA and EIA Directives could be further improved by better stewardship of impact assessment. As far as the SEA Directive is concerned, it would become more effective if it were also applied to policies or voluntary plans and programmes, underlining the need for sustainable and efficient use of soil resources, considering demographic and regional conditions and the vast potential for inner urban redevelopment.

Indeed, existing relationships between zoning and the physical structure of urban contexts suggest that the evaluation of environmental consequences must become an integral part of the planning process. This means that it is essential to identify suitable approaches, instruments and indicators for land consumption assessment in order to implement 
principles and models for sustainable local urban development. Increasing attention to the SEA process and its complexity shows that it is necessary to apply SEA in the earliest stages of the plan and/or programme decision-making process so that it can become truly effective in improving the organization of the different phases and render the evaluation operational. It also becomes necessary to determine the stage of the decision-making process in which it is most appropriate for the integration of SEA approaches and techniques. In particular, complete integration of SEA in planning requires correct understanding of the decision-making process in its different phases, along with the identification of specific contributions from the different professional fields involved. Decisions are made after considering a number of different and sometimes conflicting points of view; variables containing environmental issues are only one of the aspects taken into account in an interdisciplinary approach. Developing an SEA process in an integrated and participatory manner means considering how different points of view, components and values can contribute to understanding key issues and the selection of alternatives.

The structure of the SEA process as a tool to support decision-making should adapt to the type and content of the plan or programme in question and the relative procedural phases without compromising the specific nature of the approach itself. At the same time, it is essential to combine different techniques and tools within the same framework, integrating a variety of evaluation tools in order to define a multi-methodological framework that can analyze and tackle different issues. In particular, certain methods offer the possibility of combining Multi-Criteria Analysis and Multi-Group Analysis with Geographical Information Systems (GIS), Internet Technology, Spatial Decision Support Systems, and Cellular Automata Models, contributing to the construction of a Dynamic Spatial Decision Support System (Cerreta and De Toro, 2012a; Fusco Girard and Torre, 2012; Perchinunno et al., 2012). A wide variety of territorial information can be easily combined and related to the characteristics of the different land use options, facilitating the construction of appropriate indicators and improving impact forecasting, leading to a priority list of preferences regarding the various options.

In particular, integration of Multi-Criteria Analysis, MultiGroup Analysis and GIS can be especially useful in the presence of strong environmental and social conflict, such as land consumption or land take, in which the role of local resources and social actors - and their relations and objectives - can be considered determining factors in the development of a dynamic spatial evaluation model. In this process, spatial analysis, performed using spatial data, can include methods for exploring the spatial relationships between real and theoretical features, extracting or creating new information about a set of geographic characteristics (techniques to determine the distribution of a spatial feature, the relationships between two or more features, etc.), the study of their locations and forms, and the relationships between them. Integration of Multi-Criteria Analysis, Multi-Group Analysis and GIS supports the definition of a spatial multi-criteria decisionmaking process involving a set of geographically defined alternatives that can be compared with respect to a given set of evaluation criteria, taking into account decision-makers' preferences (Cerreta et al., 2012; Cerreta and Mele, 2012). This means that results of the analysis depend not only on the geographic distribution of attributes but also on value judgments involved in the decision-making process. Spatial analysis combined with multi-criteria methods has been used in recent years to support evaluation, especially in the field of land use planning, and can be a useful approach for facing the key issues relating to land consumption.

In light of this point of view, the proposal of a multimethodological evaluative framework can help generate more efficient and effective results than sector-specific approaches. Integrated Spatial Assessment (ISA) (Fusco Girard and De Toro, 2007; Cerreta and De Toro, 2010, 2012b,c) can be useful for the recognition of tangible and intangible values, including the development and definition of goals, the sharing of knowledge, negotiation and compromise, and needs evaluation. The proposed approach can help communities clarify values, become more adaptive and proactive, respond to change, set personal and collective goals, and participate in the decision-making process. At the same time, the application of spatial tools is useful in identifying territorial attributes linking values and planning choices.

\section{An Integrated Spatial Assessment (ISA) approach for the Montecorvino Rovella City Plan}

\subsection{Urbanization suitability maps}

The Integrated Spatial Assessment (ISA) approach was applied to the new City Plan for the municipality of Montecorvino Rovella in the Province of Salerno in Southern Italy (Fig. 1). Throughout the experiment, the goal was to develop a new methodology that could help recognize principal values, create greater cohesion regarding environmental protection and the safeguarding of local resources, and stimulate the reduction of soil consumption for more sustainable territorial uses. The ISA approach can also help identify territorial impacts deriving from plan strategies and actions.

In order to structure a Dynamic Spatial Decision MakingProcess, the environmental complexity was explored by taking into account a smaller number of essential elements in order to provide useful strategic information that can schematically represent the territory's multidimensional quality. Therefore, the tools used in this process were the following:

1. for pinpointed construction of knowledge of local resources: a system of suitable environmental indicators was identified that could analyze both existing conditions, considering current values, as well 


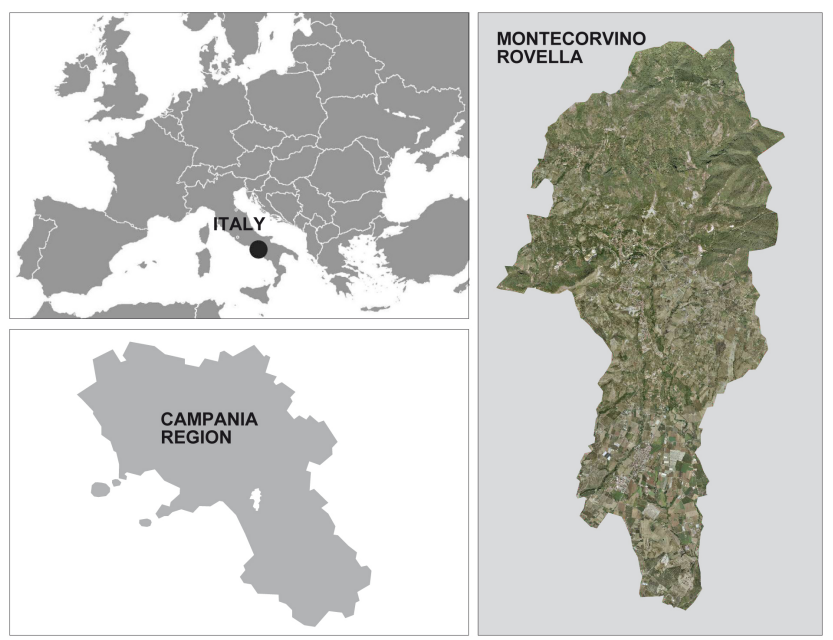

Fig. 1. Location of Montecorvino Rovella.

as scenarios for possible development, identifying the foreseen values;

2. for analysis of territorial and environmental characteristics: a GIS was realized that contained geological data, agricultural land use, and general territorial system;

3. for assessment of the plan alternatives: the multicriteria method, Analytic Hierarchy Process (AHP) (Saaty, 1980), was integrated with the GIS to foresee, in spatial terms, the impact of the plan on the different environmental components and to identify sustainable strategies for action.

In order to analyze the opportunity for the plan to reduce land consumption through the AHP multicriteria method integrated with GIS, "urbanization suitability maps" were generated; they expressed the greater or lesser propensity of the territory to "receive" development, considering its potential impacts.

The application of the AHP method is particularly important for structuring the decision-making process in hierarchical form (Saaty, 1980, 1992). This approach consists of three main phases:

1. construction of a suitable hierarchy;

2. definition of priorities between elements in the hierarchy by means of pairwise comparisons;

3. verification of the logical consistency of pairwise comparisons.

The first step is based on findings indicating that, when processing information, the human mind recognizes objects and concepts identifying relationships between them. Because the human mind cannot perceive all factors affected by an action and their connections simultaneously, it helps to break down complex systems into simple structures. This simplification is made possible by means of a logical process with the goal of constructing suitable hierarchies.

The second step is carried out through pairwise comparisons (i.e. comparing elements in pairs with respect to a given criterion) which are used for establishing priorities (or weights) among elements belonging to same hierarchical level. They are compared in pairs with respect to the corresponding elements in the next higher level, obtaining a matrix of pairwise comparisons.

In order to represent the relative importance of one element over another, a suitable evaluation scale is introduced, also known as "Saaty's scale", which defines and explains the values 1-9 assigned to the judgments in comparing pairs of elements in each level with respect to a criterion in the next higher level. Pairwise comparisons are organized in appropriate matrices; for each, the so-called "vectors of priorities" are calculated (expressed on the scale $0-1$, by means of the normalization of principal eigenvector of the matrix) which, when aggregated, provide a complete ranking among alternatives.

The third step considers that, in comparing elements, inconsistency of a certain degree can arise. In the AHP approach a "consistency ratio" of each matrix of pairwise comparisons is computed to check the degree of inconsistency, using the calculation of the matrix's principal eigenvalue. Indeed, a consistency ratio of 0.10 or less is considered acceptable; if this ratio is greater than 0.10 , it is necessary to reformulate judgments by means of new pairwise comparisons.

In the present case-study, the urbanization process was analyzed considering the assessment of land consumption according to different criteria and indicators. Evaluation criteria were organized according to a three-tiered hierarchical structure (Table 1).

Some spatial indicators linked to a value judgment expressed on a six-point scale were associated with the criteria of the third hierarchical level:

- high urbanization suitability (score 5);

- medium-high urbanization suitability (score 4);

- medium urbanization suitability (score 3);

- medium-low urbanization suitability (score 2);

- low urbanization suitability (score 1);

- no urbanization suitability (score 0 ).

For each urbanization suitability class, a numerical value (score) and a chromatic scale were associated with the six judgments expressed by the expert members of the City Plan working group. To produce the graphic representation of the results, the color attributed to each pixel was associated with each score according to the conventional range from dark green to red (Table 2). The processing of each selected spatial indicator considers the data and information provided 
Table 1. Hierarchical structure of criteria and indicators for the urbanization process.

\begin{tabular}{|c|c|c|c|c|c|}
\hline $\begin{array}{l}\text { Criteria of the } \\
\text { 1st level }\end{array}$ & $\begin{array}{l}\text { Criteria of } \\
\text { the } 2 \text { nd level }\end{array}$ & $\begin{array}{l}\text { Criteria of the } \\
\text { 3rd level }\end{array}$ & Indicators & Suitability & Scores \\
\hline \multirow[t]{5}{*}{ Geomorphology } & \multirow[t]{3}{*}{ Geology } & Slope stability & $\begin{array}{l}\text { Very high degree of danger } \\
\text { High degree of danger } \\
\text { Medium degree of danger } \\
\text { Moderate degree of danger } \\
\text { Stable zones } \\
\text { Quarries }\end{array}$ & $\begin{array}{l}\text { None } \\
\text { Low } \\
\text { Medium-low } \\
\text { Medium } \\
\text { High } \\
\text { None }\end{array}$ & $\begin{array}{l}0 \\
1 \\
2 \\
3 \\
5 \\
0\end{array}$ \\
\hline & & Soil permeability & $\begin{array}{l}\text { Low-permeable and impermeable soils } \\
\text { Permeable soils (porosity) } \\
\text { Permeable soils (fractures and carsism) }\end{array}$ & $\begin{array}{l}\text { High } \\
\text { Medium } \\
\text { Low }\end{array}$ & $\begin{array}{l}5 \\
3 \\
1\end{array}$ \\
\hline & & Seismic zoning & $\begin{array}{l}\text { Rocks } \\
\text { Conglomerates } \\
\text { Clay soils } \\
\text { Alluvium } \\
\text { Scree }\end{array}$ & $\begin{array}{l}\text { High } \\
\text { Medium-high } \\
\text { Medium } \\
\text { Medium-low } \\
\text { Low }\end{array}$ & $\begin{array}{l}5 \\
4 \\
3 \\
2 \\
1\end{array}$ \\
\hline & \multirow[t]{2}{*}{ Morphology } & Slope classes & $\begin{array}{l}\text { Zones with less than } 10 \% \text { gradient } \\
\text { Zones between } 10 \text { and } 20 \% \text { gradient } \\
\text { Zones between } 20 \text { and } 30 \% \text { gradient } \\
\text { Zones between } 30 \text { and } 50 \% \text { gradient } \\
\text { Zones with greater than } 50 \% \text { gradient }\end{array}$ & $\begin{array}{l}\text { High } \\
\text { Medium } \\
\text { Low } \\
\text { None } \\
\text { None }\end{array}$ & $\begin{array}{l}5 \\
3 \\
1 \\
0 \\
0\end{array}$ \\
\hline & & Altimetry & $\begin{array}{l}\text { Zones between } 17 \text { and } 250 \mathrm{~m} \text { a.s.l. } \\
\text { Zones between } 250 \text { and } 500 \mathrm{~m} \text { a.s.l. } \\
\text { Zones between } 500 \text { and } 1178 \mathrm{~m} \text { a.s.l. }\end{array}$ & $\begin{array}{l}\text { High } \\
\text { Medium } \\
\text { Low }\end{array}$ & $\begin{array}{l}5 \\
3 \\
1\end{array}$ \\
\hline \multirow[t]{5}{*}{$\begin{array}{l}\text { Natural resources and } \\
\text { ecological network }\end{array}$} & \multirow[t]{2}{*}{ Natural resources } & Agriculture land use & $\begin{array}{l}\text { Grazing, grassland and wood } \\
\text { Grazing and grassland } \\
\text { Maquis shrubland } \\
\text { Olive grove } \\
\text { Tree cultivation and grazing } \\
\text { Tree cultivation and olive grove } \\
\text { Tree cultivation } \\
\text { Arable farming and tree cultivation } \\
\text { Arable farming } \\
\text { Uncultivated land } \\
\text { Non-agricultural land }\end{array}$ & $\begin{array}{l}\text { None } \\
\text { None } \\
\text { None } \\
\text { None } \\
\text { Low } \\
\text { Low } \\
\text { Low } \\
\text { Medium-low } \\
\text { Medium } \\
\text { High } \\
\text { High }\end{array}$ & $\begin{array}{l}0 \\
0 \\
0 \\
0 \\
1 \\
1 \\
1 \\
2 \\
3 \\
5 \\
5\end{array}$ \\
\hline & & Soil fertility & $\begin{array}{l}\text { Good fertility } \\
\text { Sufficient fertility } \\
\text { Low fertility }\end{array}$ & $\begin{array}{l}\text { Low } \\
\text { Medium } \\
\text { High }\end{array}$ & $\begin{array}{l}1 \\
3 \\
5\end{array}$ \\
\hline & \multirow[t]{3}{*}{ Ecological network } & Natural Park & $\begin{array}{l}\text { Zones in the Park } \\
\text { Zones outside the Park }\end{array}$ & $\begin{array}{l}\text { Low } \\
\text { High }\end{array}$ & $\begin{array}{l}1 \\
5\end{array}$ \\
\hline & & Site of Community Importance & $\begin{array}{l}\text { Zones in the Site of Community Importance } \\
\text { Zones outside the Site of Community Importance }\end{array}$ & $\begin{array}{l}\text { Low } \\
\text { High }\end{array}$ & $\begin{array}{l}1 \\
5\end{array}$ \\
\hline & & Special Protection Areas & $\begin{array}{l}\text { Zones in the Special Protections Areas } \\
\text { Zones outside the Special Protections Areas }\end{array}$ & $\begin{array}{l}\text { Low } \\
\text { High }\end{array}$ & $\begin{array}{l}1 \\
5\end{array}$ \\
\hline
\end{tabular}

above all by the studies conducted by the agronomist, geologist, planner and the Montecorvino Rovella municipality Office Plan for the new City Plan; they are valid up to 2010. To conduct "spatial assessment", an extension of the AHP method within ArcGIS was used (Marinoni, 2004; Marinoni and Hoppe, 2006; Zelenović Vasiljevic et al., 2009), obtaining the "urbanization suitability maps". With this approach, it was possible to obtain not only a simple overlay of the different themes, but to conduct a pairwise comparison of the criteria of each hierarchical level, assigning a weight (expression of an expert judgment) on a scale of 0-1 to each criterion through the calculation of the principal eigenvector of the pairwise comparison matrixes.
Table 2. Scores and colors assigned to the different urbanization suitabilities.

\begin{tabular}{lrl}
\hline $\begin{array}{l}\text { Urbanization } \\
\text { suitability }\end{array}$ & Score & Color \\
\hline High & 5 & Dark green \\
Medium-high & 4 & Light green \\
Medium & 3 & Light yellow \\
Medium-low & 2 & Dark yellow \\
Low & 1 & Orange \\
None & 0 & Red \\
\hline
\end{tabular}




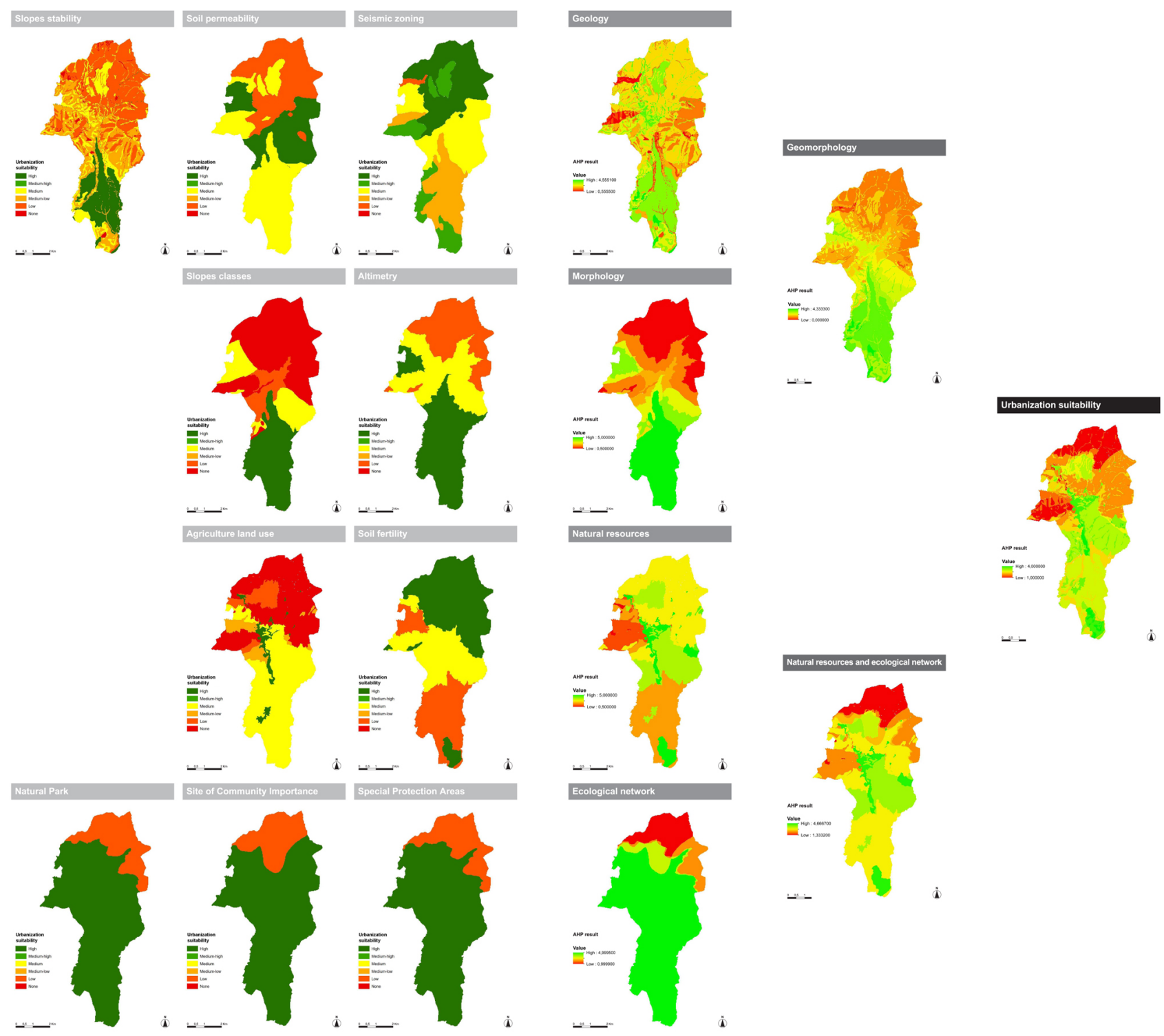

Fig. 2. Hierarchical structure of criteria for the urbanization process.

It should be highlighted that a first pairwise comparison matrix contains the criteria of the first hierarchical level ("geomorphology" and "natural resources and ecological network").

For the second hierarchical level, two pairwise comparison matrixes were necessary: "geology" and "morphology"; "natural resources" and "ecological network".

In the same way, for the third hierarchical level four pairwise comparison matrixes were deemed necessary: "slopes stability", "soil permeability", and "seismic zoning"; "slope classes" and "altimetry"; "agriculture land use" and "soil fertility"; "natural park", "site of community importance", and "special protection areas".

Using a raster approach in each pairwise comparison and for each pixel, it was possible to obtain a total value as a linear combination of the criteria weights by the score relating to urbanization suitability. In particular, the geometric resolution adopted is $25 \times 25 \mathrm{~m}$; the map projection is UTM and datum is WGS $198433 \mathrm{~N}$.

The hierarchical structure of all the urbanization criteria is illustrated in Fig. 2. For example, if we consider "geology", we obtained the maps in Fig. 3 that show the scores assigned to the respective criterion (slope stability, soil permeability and seismic zoning). In making a linear combination among weights and scores relative to these three criteria (i.e. calculating the priority vector in the AHP method), we obtained the results in the last map of Fig. 3. It is possible to apply the same procedure to the "morphology" criterion and the results can be combined with those relating to "geology" (both belonging to the second hierarchical level) thus 

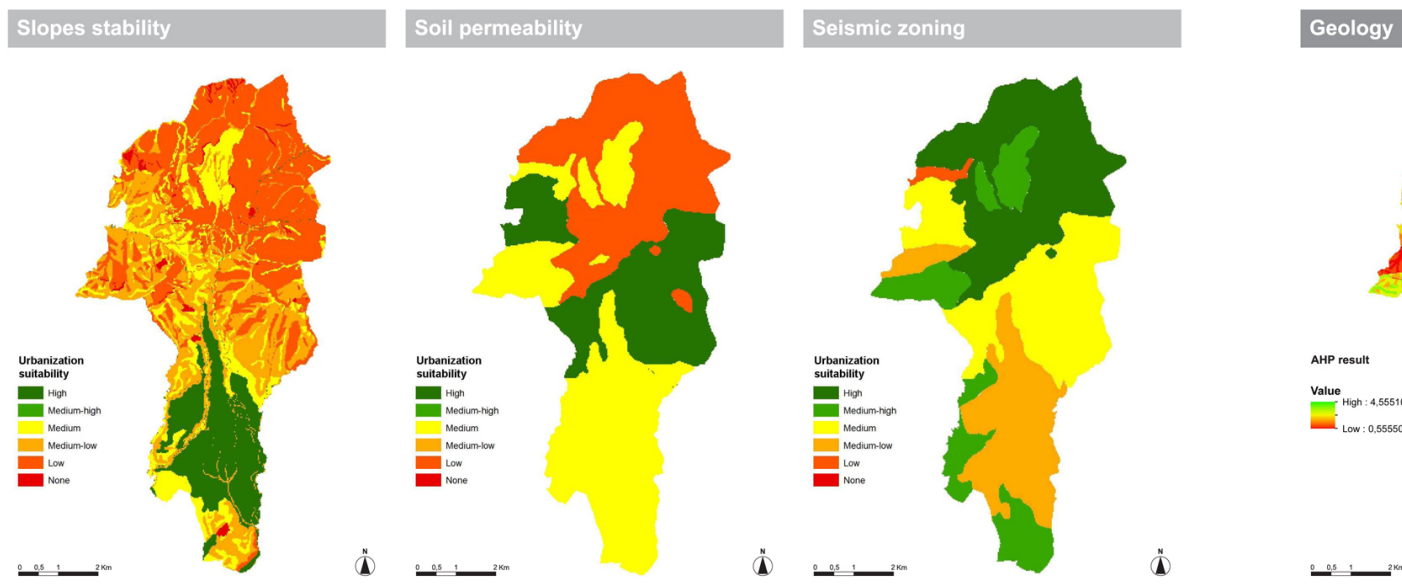

Fig. 3. Urbanization suitability maps: geology.

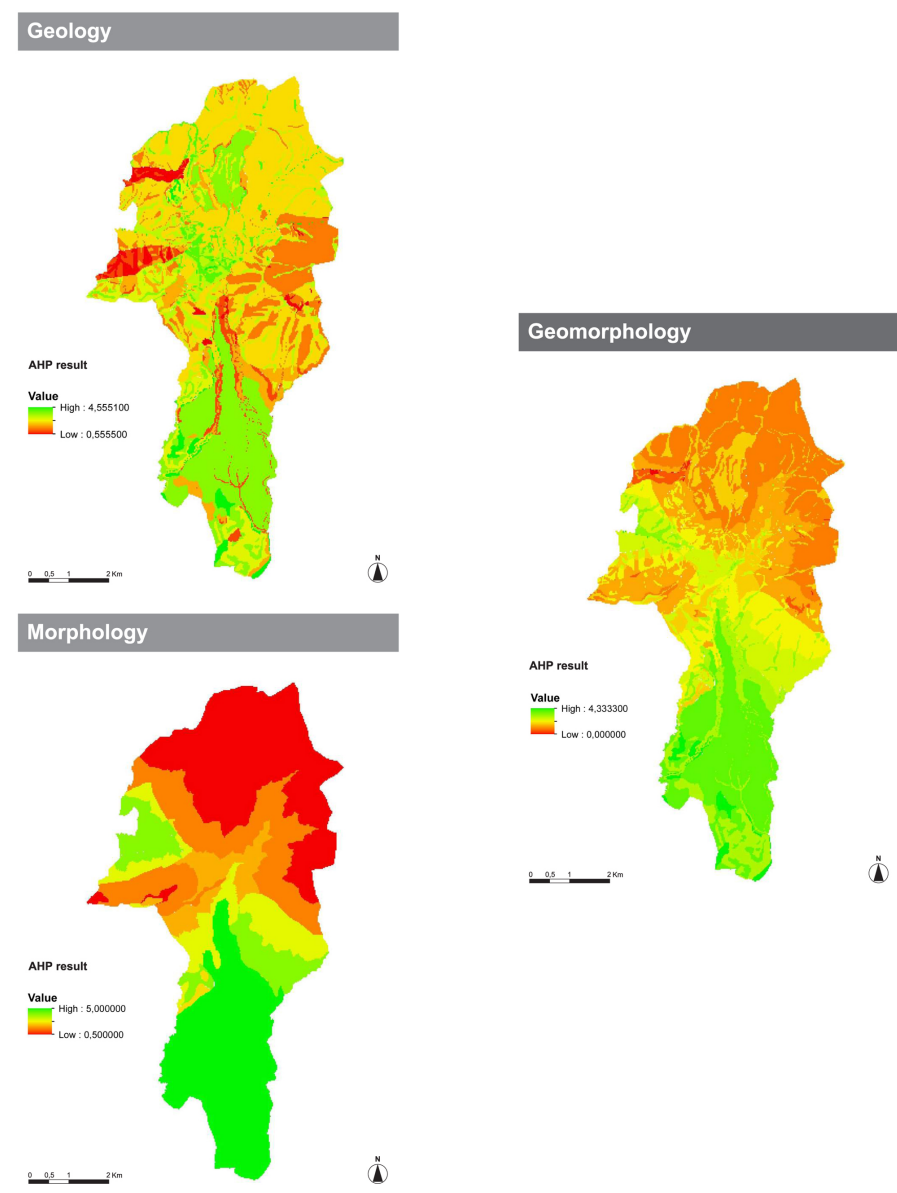

Fig. 4. Urbanization suitability maps: geomorphology.

obtaining urbanization suitability for the criterion "geomorphology" (belonging to the first hierarchical level) as seen in Fig. 4.

In the same way, we obtained the maps for "natural resources and ecological network" as shown in Fig. 5.
Therefore, considering all the criteria in the hierarchy and combining the data of all criteria belonging to the first hierarchical level, we obtained the map in Fig. 6, in which the colors - from dark green to red - express the urbanization suitability (from high to none) of the Montecorvino 


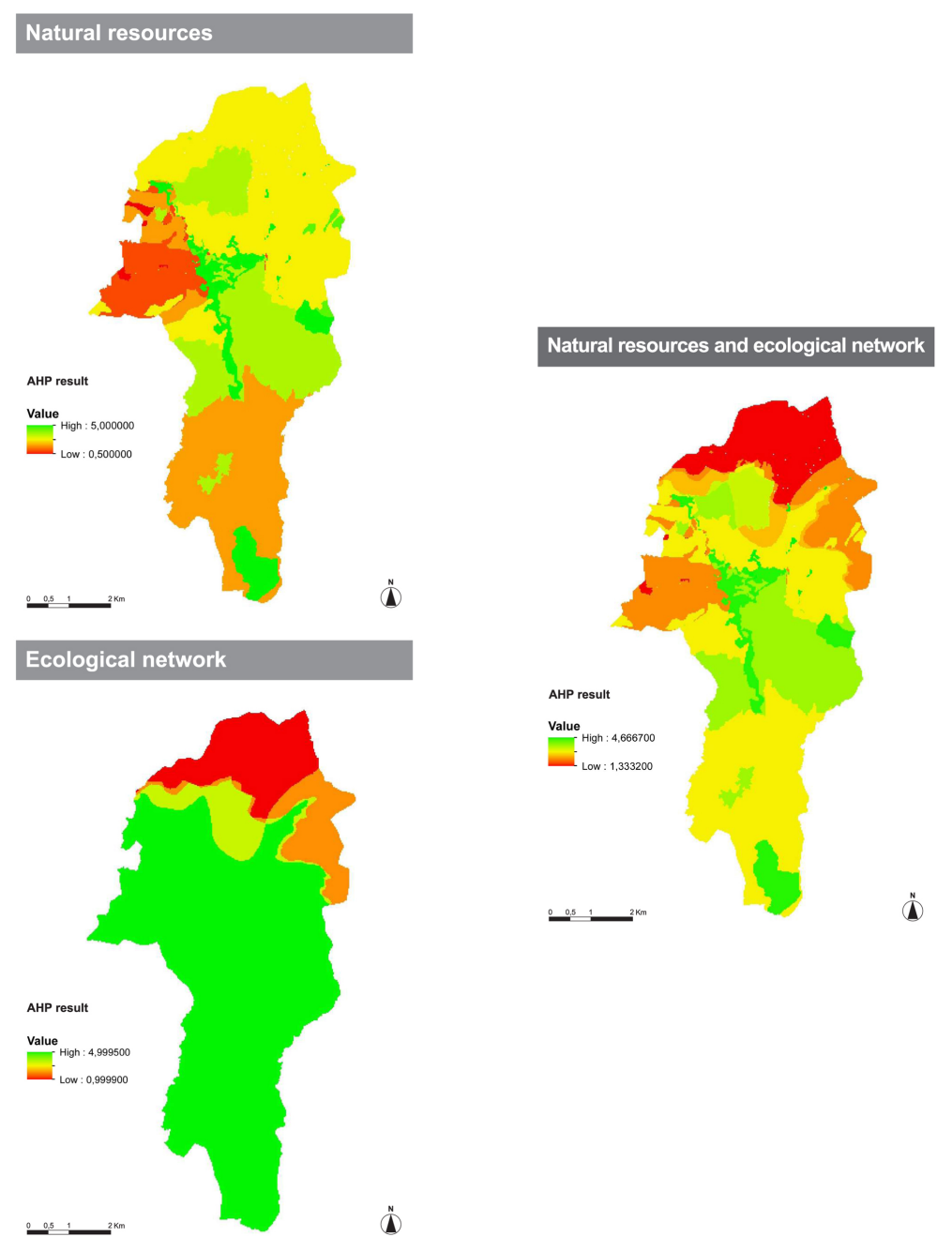

Fig. 5. Urbanization suitability maps: natural resources and ecological network.

Rovella territory. According to this approach, the assessment can truly support the planning process, enhancing the potential of each area and, consequently, locating new urban development in places subject to minimum territorial and environmental impacts. Starting with these suitability maps, planners can coherently regulate land use, reducing the consumption of soil and local environmental resources.

\subsection{Land consumption, indexes and indicators}

In a regional policy context, strengthening the knowledge base is a high priority for identifying planning tools and selecting approaches and methods for assessing and monitoring the effects of the expected transformations.

As already pointed out, land consumption is one of the major phenomena upon which research and theoretical and operational studies has focused in recent years in order to define actions that can achieve the correct balance between development prospects and the need to preserve soil resources.
In particular, initial attention on the measurement of the total land used was followed by studies to link land use to different themes and disciplines that affect it. Indeed, from land consumption due to urban development, we also considered land used for infrastructure, technical services relating to energy production, technological facilities or mining activities.

In this way, knowledge of issues relating to this phenomenon has been progressively expanded, both in quantity and in quality, not only in reference to urban growth but also to its impact on agricultural activities, natural resources and landscape (Fichera et al., 2012; Vizzari, 2011).

The complexity of this issue requires shared methodologies for the measurement of the phenomenon in order to ensure the comparison of the data examined in relation to policies undertaken, to planning models to be implemented on all government levels, and to the evaluation processes associated with the different plan types. 


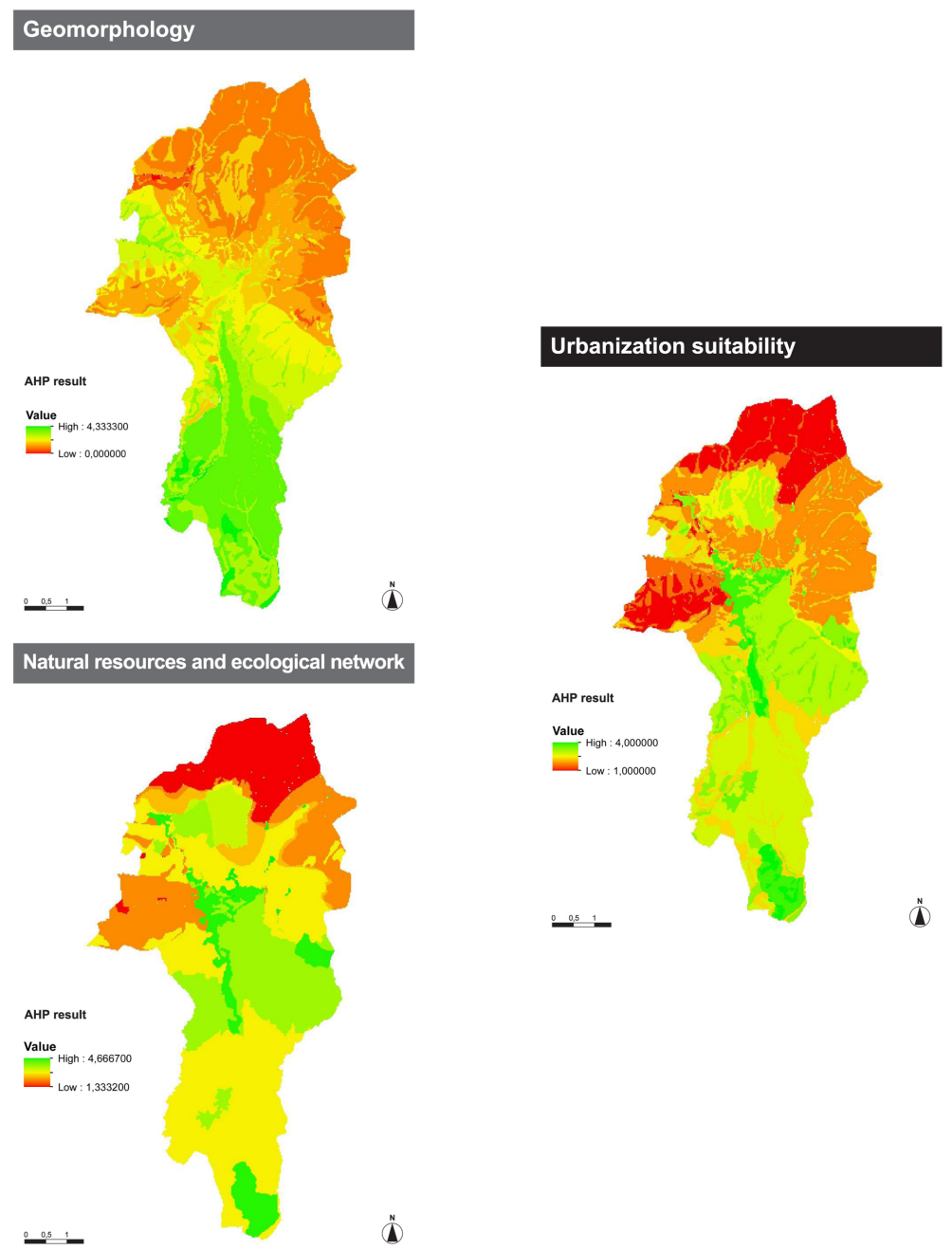

Fig. 6. Composite urbanization suitability map.

In compliance with European Union requirements, it is possible to identify an appropriate set of indexes and indicators useful for directing intervention strategies and plan choices towards the effective limitation of land consumption. As indicated by the Organization for Economic Co-operation and Development (OECD), indexes/indicators are parameters relating to an environmental phenomenon that can provide information on the characteristics of the phenomenon as a whole (OECD, 2003).

Their function is to indicate the state (or the change in state) of a complex phenomenon which is not directly measured. The use of indexes/indicators makes it possible to synthetically represent the investigated problem, maintaining unchanged the content of the analysis conducted.

These properties render indicators and indexes technical tools of knowledge and control that are communicable and understandable; they can play a strategic role in facilitating and making planning decision-making processes more objective, effective and transparent. An interesting example of indicator selection is the Sustainable Seattle (1993) experience which, starting from the first indicator report in 1993, Indicators of Sustainable Community, developed a more plentiful system of indicators that can present information in an accessible, meaningful and actionable way (Holden, 2006; Holman, 2009).

The need to express the complexity of a phenomenon analyzed in exhaustive terms led to the identification of an evaluation approach focused on different indicators and indices - correlated from a logical and functional point of view that can describe and relate both the different connotations that land consumption can take on as well as the processes of regional transformation connected to it.

Land consumption must be considered a dynamic process that alters the nature of a region from natural to artificial conditions; soil sealing is the last stage in this process (EEA, 2005). Based on the guidelines and procedures developed by the European Environment Agency (EEA) to support the European Union in assessing land use sustainability, monitoring 


\section{Existing urbanization}

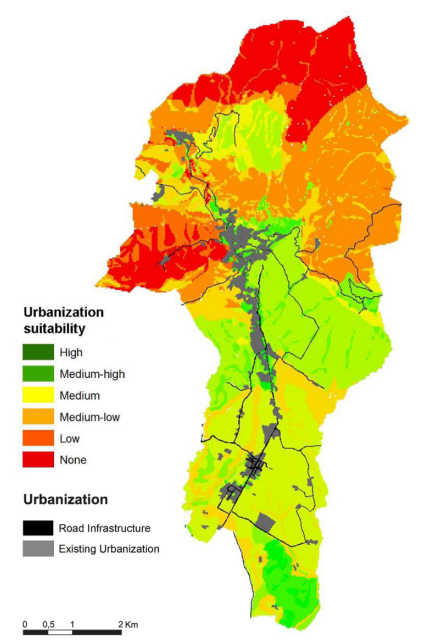

City Plan

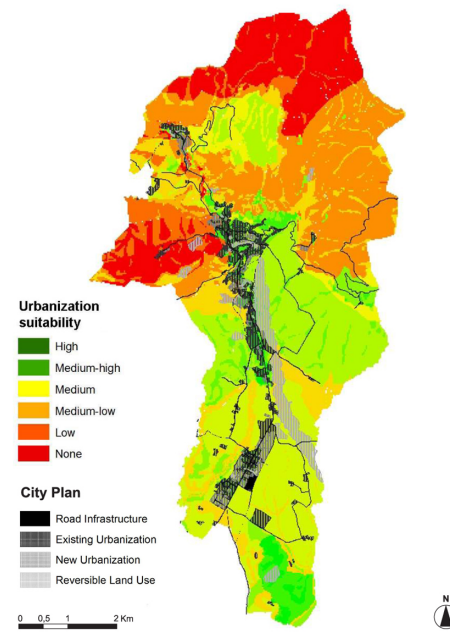

Fig. 7. Land consumption before and after the City Plan.

and definition of strategies (EEA, 2001), it was possible to select some suitable indicators and indexes.

In particular, despite the abundance of indicators illustrated in literature (Ochola and Kerkides, 2004; Fusco Girard, 2009; Montrone et al., 2010; Weiland et al., 2011; Mattila et al., 2012; Selicato et al., 2012; van Oudenhoven et al., 2012), in order to define the land use strategies for Montecorvino Rovella, we identified only those that could assess the contribution of the different environmental components present. Taking into account the results obtained from drafting the urbanization suitability maps, land consumption before and after City Plan implementation was assessed. In this way, it became possible to analyze the possible effects of the City Plan strategies on land consumption (Fig. 7).

In particular, five main indexes were selected (Regione Piemonte, 2012) taking into account the characteristics of the territory and plan actions:

1. Land Consumption index for Infrastructure (LCI): to assess the percentage of land area used by infrastructure outside the urbanized area;

2. Land Consumption index for Urbanized areas (LCU): to assess the percentage of land transformed for the creation of urbanized areas at the expense of agricultural or natural uses;

3. Reversible Land Consumption index (RLC): to identify the percentage of natural land area converted to activities that modify land use without soil sealing (like urban parks, sports facilities, etc.);

4. Irreversible Land Consumption index (ILC): the sum of Land Consumption index for Infrastructure (LCI) and Land Consumption index for Urbanized areas (LCU); it identifies the overall percentage of land irreversibly consumed;

5. Total Land Consumption index (TLC): the sum of Reversible Land Consumption index (RLC) and Irreversible Land Consumption index (ILC).

Table 3 illustrates the five indexes calculated by analyzing the present situation and scenarios that might result from the implementation of City Plan strategies.

It is possible to observe how the value of LCI increases with the realization of City Plan strategies, going from 0.67 to $0.97 \%$; while the value of LCU is reduced considerably, from 3.74 to $1.25 \%$. An interesting aspect is also the positive increase in RLC, from 0.64 to $2.27 \%$. Therefore, it is possible to highlight how the City Plan sought to increase actions that transform the territory in a reversible way. In any case, the value of ILC increases from 4.40 to $6.22 \%$, and the value of TLC is changed from 5.04 to $8.50 \%$. It is evident that the City Plan actions lead to an increase in land consumption, but it is equally important to note that one of the goals is to focus more on actions that involve reversible land consumption.

Moreover, new urbanization and reversible land uses are located in areas characterized by greater urbanization suitability, identified by the combined approach of the AHP method and GIS as "high", "medium-high" and "medium" (Fig. 7). If we consider the composite urbanization suitability map and existing urbanization, we can analyze how the process of land consumption today characterizes Montecorvino Rovella (Fig. 8). At the same time, applying the proposed approach of integrated methods and tools (Fig. 9), it is possible to locate new transformations in places where territorial and environmental impacts can be minimized, supporting a transparent and dynamic decision-making process that takes into 
Table 3. Indexes of land consumption.

\begin{tabular}{|c|c|}
\hline Current values & Plan implementation \\
\hline \multicolumn{2}{|c|}{ 1. Land Consumption index for Infrastructure (LCI) } \\
\hline $\begin{array}{l}\text { In }=\text { Infrastructure }=28.1 \mathrm{~km}^{2} \\
\mathrm{Ta}=\text { Total land area }=4208 \mathrm{~km}^{2} \\
\mathrm{LCI}=\mathrm{In} / \mathrm{Ta} \times 100=0.67 \%\end{array}$ & $\begin{array}{l}\text { In }=\text { Infrastructure }=40.8 \mathrm{~km}^{2} \\
\mathrm{Ta}=\text { Total land area }=4208 \mathrm{~km}^{2} \\
\mathrm{LCI}=\mathrm{In} / \mathrm{Ta} \times 100=0.97 \%\end{array}$ \\
\hline \multicolumn{2}{|c|}{ 2. Land Consumption index for Urbanized areas (LCU) } \\
\hline $\begin{array}{l}\mathrm{Ua}=\text { Urbanized land area }=157.2 \mathrm{~km}^{2} \\
\mathrm{Ta}=\text { Total land area }=4208 \mathrm{~km}^{2} \\
\mathrm{LCU}=\mathrm{Ua} / \mathrm{Ta} \times 100=3.74 \%\end{array}$ & $\begin{array}{l}\mathrm{Ua}=\text { Urbanized land area }=221.1 \mathrm{~km}^{2} \\
\mathrm{Ta}=\text { Total land area }=4208 \mathrm{~km}^{2} \\
\mathrm{LCU}=\mathrm{Ua} / \mathrm{Ta} \times 100=1.25 \%\end{array}$ \\
\hline \multicolumn{2}{|c|}{ 3. Reversible Land Consumption index (RLC) } \\
\hline $\begin{array}{l}\mathrm{Ra}=\text { Reversible land area }=26.9 \mathrm{~km}^{2} \\
\mathrm{Ta}=\text { Total land area }=4208 \mathrm{~km}^{2} \\
\mathrm{RLC}=\mathrm{Ra} / \mathrm{Ta} \times 100=0.64 \%\end{array}$ & $\begin{array}{l}\mathrm{Ra}=\text { Reversible land area }=95.6 \mathrm{~km}^{2} \\
\mathrm{Ta}=\text { Total land area }=4208 \mathrm{~km}^{2} \\
\mathrm{RLC}=\mathrm{Ra} / \mathrm{Ta} \times 100=2.27 \%\end{array}$ \\
\hline \multicolumn{2}{|c|}{ 4. Irreversible Land Consumption index (ILC) } \\
\hline $\mathrm{ILC}=\mathrm{LCI}+\mathrm{LCU}=4.40 \%$ & $\mathrm{ILC}=\mathrm{LCI}+\mathrm{LCU}=6.22 \%$ \\
\hline \multicolumn{2}{|l|}{ 5. Total Land Consumption index (TLC) } \\
\hline $\mathrm{TLC}=\mathrm{RLC}+\mathrm{ILC}=5.04 \%$ & $\mathrm{TLC}=\mathrm{RLC}+\mathrm{ILC}=8.50 \%$ \\
\hline
\end{tabular}

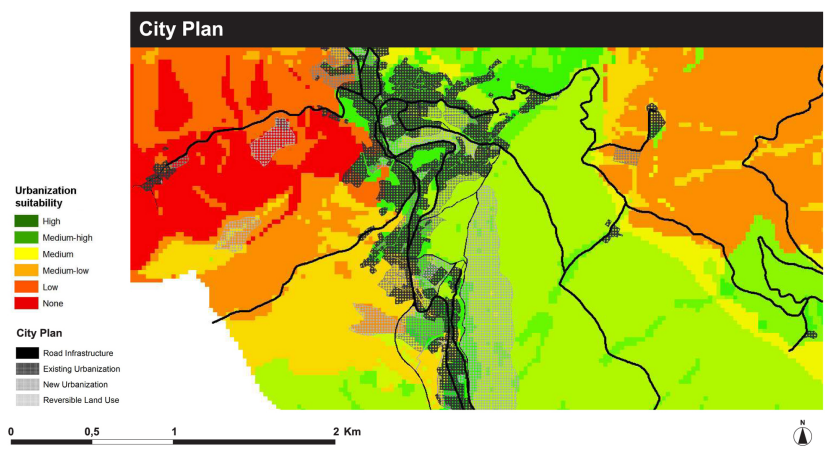

Fig. 8. Example of City Plan land use.

account multidimensional criteria and the specificity of local resources.

\section{Discussion and conclusions}

According to The European Environment - State and Outlook 2010 (EEA, 2010c), today's main environmental challenges are characterized by their systemic nature and the necessity of facing them by taking into account their interactions. Indeed, the assessments of four environmental priority areas (climate change, nature and biodiversity, use of natural resources and waste, and environment and health) point to a series of direct and indirect links between the environmental challenges. Thus, many of the links are direct, for example

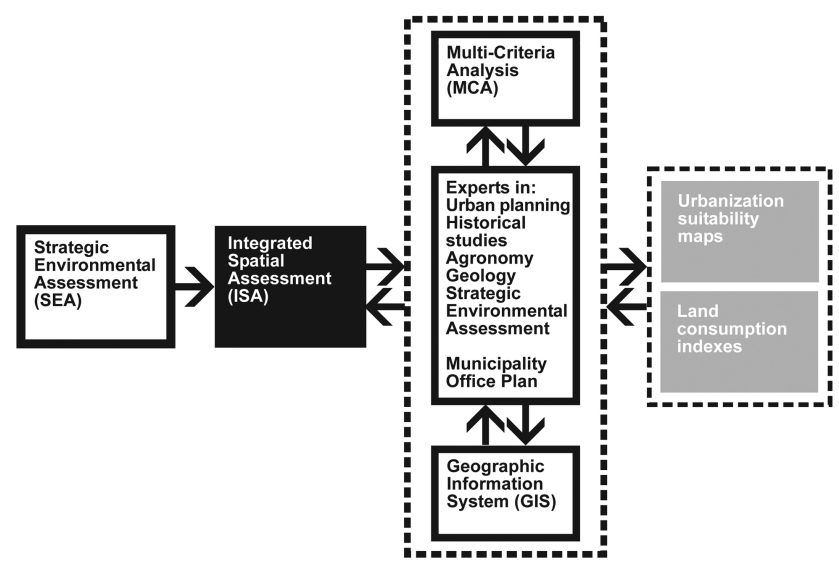

Fig. 9. Methodology.

when changes in the state of one environmental issue can translate directly into pressures on another. Or they are indirect when changes in one environmental question result in feedback from another and vice versa.

In particular, land use and land cover changes exemplify such indirect links: they can be seen to be both drivers and impacts, not only of climate change but also of biodiversity loss and the use of natural resources. For example, any change in land use and land cover resulting from urbanization or the conversion of forests to agriculture (Di Fazio et al., 2011; Fichera et al., 2011), affects climate as well as biodiversity. At the same time, many changes in the state of 
the environment are due to unsustainable consumption and production patterns. Land use and land cover are the principal drivers of environmental change, influencing landscapes and the distribution and functioning of ecosystems, answering our demands for food, forest products, renewable energy and urbanization (CLC, 2012).

Any policy or strategy for land conservation and sustainable management cannot be possible without a careful and thorough analytical process in order to monitor the phenomenon in terms of quality and quantity, to understand causes, to recognize results and to develop effective mitigation measures that can be integrated with concrete planning actions. Therefore, a system of spatial and dynamic knowledge is necessary; it must contain reliable and easily comparable data to guide and support the decisions of planners and policy makers in limiting the consumption and waste of soil resources.

Existing best practices designed to limit, mitigate and compensate soil sealing show that sound spatial planning follows an integrated approach, requiring the full commitment of all related public authorities, in particular those governing bodies (e.g. municipalities, regions, etc.) normally responsible for land management. Another important aspect is that specific regional approaches must be developed that take into account unused resources on the local level (for example, a particularly large number of empty buildings or brownfield sites). Furthermore, existing funding policies for infrastructure development have been carefully reviewed, leading to a reduction of those subsidies that drive unsustainable land take and soil sealing, also considering the goals of lowering the share of urbanization fees in municipal budgets (EC, 2012).

The goal of limiting land consumption, therefore, requires a multidisciplinary approach with strict integration between regional policies on different levels and sectorial policies, including spatial planning and such strategic sectors as legislation, plans, programs, and evaluation tools. Indeed, according to the Italian planning system, the city plan is still a land use plan starting from a structure plan, in which land consumption and land use monitoring are particularly important.

Land use monitoring, as well its conditions, can help to define appropriate policies that, through planning, can help implement sustainable land management and contribute to creating collective awareness regarding soil as a common good, so that its protection should be preferred to its conversion.

The present case study proposes a selection of useful spatial and territorial indicators based on available data sources; it uses a different approach by introducing environmental reporting units as the basis for the calculation and representation of the information. The indicators are created through the spatial analysis of different information layers using GIS combined with the AHP method.

The goal of this approach was to better illustrate the territorial diversity of the natural environment and to assess related impacts of the urbanization process. The specificity of the spatial and territorial indicators obtained helps address the environmental information in terms that are relevant for the local resources. This case study is, thus, an attempt to create territorial indicators that can describe the potential and critical aspects of an urbanization process in a field of investigation which requires further study and development. Indeed, dynamic spatial indicators and the use of maps for reporting and assessing soil sealing and land consumption can be powerful ways of communicating with planners and policy makers, and should therefore become part of the tools used in regional and urban transformation processes.

Acknowledgements. The authors wish to thank all members of the working group for the drafting of the new City Plan of Montercorvino Rovella: Michelangelo Russo (Urban planning); Giuseppe Guida (Project coordination); Annie Attademo, Alessandro Formisano, Tiziana Vitiello (Collaboration on urban planning); Gemma Belli (Historical studies); Luigi Daina (Agronomy); Luigi Pisapia (Geology); Paolo Carrafiello, Maria Cerreta, Pasquale De Toro (Strategic Environmental Assessment); Giuseppe Ricco, Signum Civitatis Architetti Associati, Valeria Palo (Office Plan).

Edited by: G. Borruso

\section{References}

Cerreta, M. and De Toro, P.: Integrated Spatial Assessment for a creative decision-making process: a combined methodological approach to Strategic Environmental Assessment, Int. J. Sustain. Dev., 13, 17-30, doi:10.1504/IJSD.2010.035096, 2010.

Cerreta, M. and De Toro, P.: Assessing urban transformations: A SDSS for the master plan of Castel Capuano, Naples, Lect. Notes Comput. Sci., 7334, 168-180, doi:10.1007/978-3-642-31075-1, 2012a.

Cerreta, M. and De Toro, P.: Integrated Spatial Assessment (ISA): a multi-methodological approach for planning choices, in: Advances in Spatial Planning, edited by: Burian, J., InTech, Rijeka, Croatia, 77-108, doi:10.5772/2123, 2012b.

Cerreta, M. and De Toro, P.: Strategic Environmental Assessment of Port Plans in Italy: Experiences, Approaches, Tools, Sustainability, 4, 2888-2921, doi:10.3390/su4112888, 2012c.

Cerreta, M. and Mele, R.: A landscape complex value map: integration among soft values and hard values in a spatial decision support system, Lect. Notes Comput. Sci., 7334, 653-669, doi:10.1007/978-3-642-31075-1, 2012.

Cerreta, M., Panaro, S., and Cannatella, D.: Multidimensional spatial decision-making process: local shared values in action, Lect. Notes Comput. Sci., 7334, 54-70, doi:0.1007/978-3-642-31075$1,2012$.

CLC: Corine land cover 2006 raster data - version 16, www.eea. europa.eu/data-and-maps/data/corine-land-cover-2006-raster, last access: 12 November 2012.

COM: Communication from the Commission to the Council, the European Parliament, the European Economic and Social Committee and the Committee of the Regions, 231 final, Thematic Strategy for Soil Protection, Brussels, 22 September, 2006a. 
COM: Proposal for a Directive of the European Parliament and of the Council establishing a framework for the protection of soil and amending Directive 2004/35/EC, 232 final, Brussels, 22 September, 2006 b.

COM: Report from the Commission to the Council, the European Parliament, the European Economic and Social Committee and the Committee of the Regions, On the application and effectiveness of the EIA Directive, Directive 85/337/EEC, as amended by Directives 97/11/EC and 2003/35/EC, p. 378, 2009.

COM: Communication from the Commission to the Council, the European Parliament, the European Economic and Social Committee and the Committee of the Regions, Roadmap to a Resource Efficient Europe, p. 571, 2011.

COM: Report from the Commission to the European Parliament, the Council, the European Economic and Social Committee and the Committee of the Regions, The implementation of the Soil Thematic Strategy and ongoing activities, 46 final, Brussels, 13 February 2012.

COPTA: Cooperation Platform for Territorial Cohesion, Territorial Agenda of the European Union: Towards a more competitive and sustainable Europe of diverse regions, Informal ministerial meeting on urban development and territorial cohesion, Leipzig, 2425 May 2007.

De La Rosa, D.: Soil Quality Evaluation and Monitoring based on Land Evaluation, Land Degrad. Dev., 16, 551-559, doi:10.1002/ldr.710, 2005.

Di Fazio, S., Modica, G., and Zoccali, P.: Evolution trends of land use/land cover in a Mediterranean forest landscape in Italy, Lect. Notes Comput. Sci., 6782, 284-299, doi:10.1007/978-3642-21928-3, 2011.

EC: ESDP - European Spatial Development Perspective Towards Balanced and Sustainable Development of the Territory of the European Union, Office for Official Publications of the European Communities, Luxembourg, 1999.

EC: Report from the Commission to the Council, the European Parliament, the European Economic and Social Committee and the Committee of the Regions on the application and effectiveness of the Directive of Strategic Environmental Assessment COM (2009) 469 final, 2009.

EC: Guidelines on best practice to limit, mitigate or compensate soil sealing, Commission Staff Working Document, Brussels, 2012.

EEA: Towards spatial and territorial indicators using land cover data, European Environment Agency Technical Report 59, Copenhagen, 2001.

EEA: European Environmental Agency Core Set of Indicators (CSI), European Environment Agency Technical Report, 1, Copenhagen, 2005.

EEA: Urban sprawl in Europe - The ignored challenge, European Environment Agency Technical Report 10, 2006.

EEA: Ensuring quality of life in Europe's cities and towns - tackling the environmental challenges driven by European and global change, European Environment Agency Technical Report 5, Copenhagen, 2009.

EEA: The European Environment - State and Outlook 2010, Urban Environment, European Environment Agency, Copenhagen, 2010a.

EEA: The European Environment - State and Outlook 2010, Land use, European Environment Agency, Copenhagen, $2010 \mathrm{~b}$.
EEA: The European Environment - State and Outlook 2010, Synthesis, European Environment Agency, Copenhagen, 2010c.

EEA: Green infrastructure and territorial cohesion. The concept of green infrastructure and its integration into policies using monitoring systems, European Environment Agency Technical Report 18, Copenhagen, doi:10.2800/88266, 2011.

Fichera, C. R., Modica, G., and Pollino, M.: GIS and remote sensing to study urban-rural transformation during a fifty-year period, Lect. Notes Comput. Sci., 6782, 237-252, doi:10.1007/978-3642-21928-3, 2011.

Fichera, C. R., Modica, G., and Pollino, M.: Land Cover classification and change-detection analysis using multi-temporal remote sensed imagery and landscape metrics, Ital. Eur. J. Remote Sens., 45, 1-18, doi:10.5721/EuJRS20124501, 2012.

Fusco Girard, F.: Symbioses strategies for sustainable company management, Int. J. Sustain. Dev., 12, 248-263, doi:10.1504/IJSD.2009.032780, 2009.

Fusco Girard, L. and De Toro, P.: Integrated spatial assessment: A multicriteria approach to sustainable development of cultural and environmental heritage in San Marco dei Cavoti, Italy, Central Eur. J. Operat. Res., 15, 281-299, doi:10.1007/s10100-0070031-1, 2007.

Fusco Girard, L. and Torre, C. M.: The use of Ahp in a multiactor evaluation for urban development programs: a case study, Lect. Notes Comput. Sci., 7334, 157-167, doi:10.1007/978-3642-31075-1, 2012.

Gerundo, R. and Grimaldi, M.: The measure of land consumption caused by urban planning, 2011 International Conference on Green Buildings and Sustainable Cities, Proc. Eng., 21, 11521160, doi:10.1016/j.proeng.2011.11.2124, 2011.

Hasse, J. E. and Lathrop, R. G.: Land resource impact indicators of urban sprawl, Appl. Geogr., 23, 159-175, doi:10.1016/j.apgeog.2003.08.002, 2003.

Holden, M.: Sustainable Seattle: The case of the prototype sustainability indicators project, in: Community quality-of-life indicators: Best cases II, edited by: Sirgy, M. J., Rahtz, D., and Swain, D., Springer-Verlag, Amsterdam, 177-202, 2006.

Holman, N.: Incorporating local sustainability indicators into structures of local governance: a review of the literature, Local Environ., 14, 365-375, doi:10.1080/13549830902783043, 2009.

Huang, J., Lu, X., and Sellers, J. M.: A global comparative analysis of urban form: applying spatial metrics and remote sensing, Landsc. Urban Plan, 82, 184-197, doi:10.1016/j.landurbplan.2007.02.010, 2007.

Jones, D. A., Hansen, A. J., Bly, K., Doherty, K., Verschuyl, J. P., Paugh, J. I., Carle, R., and Story, S. J.: Monitoring land use and cover around parks: A conceptual approach, Remote Sens. Environ., 113, 1346-1356, doi:10.1016/j.rse.2008.08.018, 2009.

Marinoni, O.: Implementation of the analytic hierarchy process with VBA in ArcGIS, Comput. Geosci., 30, 637-646, doi:10.1016/j.cageo.2004.03.010, 2004.

Marinoni, O. and Hoppe, A.: Using the analytic hierarchy process to support sustainable use of georesources in metropolitan areas, J. Syst. Sci. Syst. Eng., 15, 154-164, doi:10.1007/s11518-0065004-8, 2006.

Mattila, T., Helin, T., and Antikainen, R.: Land use indicators in life cycle assessment, A case study on beer production, Int. J. Life Cycle Assess., 17, 277-286, doi:10.1007/s11367-011-0353z, 2012. 
Montrone, S., Perchinunno, P., and Torre, C. M.: Analysis of positional aspects in the variation of real estate values in an Italian Southern Metropolitan area, Lect. Notes Comput. Sci., 6016, 1731, doi:10.1007/978-3-642-12156-2_2, 2010.

Ochola, W. O. and Kerkides, P.: An integrated indicatorbased spatial decision support system for land quality assessment in Kenya, Comput. Electron. Agr., 45, 3-26, doi:10.1016/j.compag.2004.05.005, 2004.

OECD: OECD Environmental Indicators. Development, measurement and use, Organization for Economic Co-operation and Development, Paris, 2003.

Peng, J., Wang, Y., Wu, J., Chang, Q., and Zhang, Y.: Evaluation for sustainable land use in mountain areas of Northwestern Yunnan Province, China, Environ. Monit. Assess., 133, 407-415, doi:10.1007/s10661-006-9595-9, 2007.

Perchinunno, P., Rotondo, F., and Torre, C. M.: The evidence of links between landscape and economy in a rural park, Int. J. Agr. Environ. Infor. Syst., 3, 72-85, doi:10.4018/jaeis.2012070105, 2012.

Piorr, A., Ravetz, J., and Tosics, I.: Periurbanisation in Europe: Towards a European policy to sustain urban-rural futures, Academic Books Life Sciences, University of Copenhagen, 2011.

Potschin, M.: Land use and the state of the natural environment, Land Use Policy, 26S, S170-S177, doi:10.1016/j.landusepol.2009.08.008, 2009.

Prokop, G., Jobstmann, H., and Schonbauer, A.: Overview on best practices for limiting soil sealing and mitigating its effects in EU27, Technical Report 50, Environment Agency Austria, Luxemburg, 2011.

Regione Piemonte: Monitoraggio del consumo di suolo in Piemonte 2012, Regione Piemonte, Torino, 2012.

Saaty, T. L.: The analytical hierarchy process, McGraw Hill, New York, NY, 1980.

Saaty, T. L.: Multicriteria decision making - The analytic hierarchy process, RWS Publications, Pittsburgh, 1992.

Schetke, S., Haase, D., and Kötter, T.: Towards sustainable settlement growth: A new multi-criteria assessment for implementing environmental targets into strategic urban planning, Environ. Impact Asses., 32, 195-210, doi:10.1016/j.eiar.2011.08.008, 2012.

Selicato, M., Torre, C. M., and La Trofa, G.: Prospect of integrate monitoring: a multidimensional approach, Lect. Notes Comput. Sci., 7334, 144-156, doi:10.1007/978-3-642-31075-1, 2012.
Sustainable Seattle: Indicators od Sustainable Community, A Report to Citizens on Long-Term Trends in our Community, Seattle, WA, 1993.

Terzi, F. and Bölen, F.: The potential effects of spatial strategies on urban sprawl in Istanbul, Urban Stud., 49, 1229-1250, doi:10.1177/0042098011410334, 2012.

Torrens, P. M.: A toolkit for measuring sprawl, Appl. Spat. Anal., 1, 5-36, doi:10.1007/s12061-008-9000-x, 2008.

Tsai, Y.: Quantifying urban form: compactness versus sprawl, Urban Stud., 42, 141-161, doi:10.1080/0042098042000309748, 2005.

Van-Camp, L., Bujarrabal, B., Gentile, A.-R., Jones, R. J. A., Montanarella, L., Olazabal, C., and Selvaradjou, S.-K.: Reports of the Technical Working Groups Established under the Thematic Strategy for Soil Protection, EUR 21319 EN, 5, Office for Official Publications of the European Communities, Luxembourg, 2004.

van Oudenhoven, A. P. E., Petz, K., Alkemade, R., Hein, L., and de Groot, R. S.: Framework for systematic indicator selection to assess effects of land management on ecosystem services, Ecol. Indic., 21, 110-122, doi:10.1016/j.ecolind.2012.01.012, 2012.

Vizzari, M.: Spatio-temporal analysis using urban-rural gradient modelling and landscape metrics, Lect. Notes Comput. Sci., 6782, 103-118, doi:10.1007/978-3-642-21928-3, 2011.

Walter, C. and Stützel, H.: A new method for assessing the sustainability of land-use systems (II): Evaluating impact indicators, Ecol. Econ., 68, 1288-1300, doi:10.1016/j.ecolecon.2008.11.016, 2009.

Weber, T., Sloan, A., and Wolf, J.: Maryland's Green Infrastructure Assessment: Development of a comprehensive approach to land conservation, Landsc. Urban Plan., 77, 94-110, doi:10.1016/j.landurbplan.2005.02.002, 2006.

Weiland, U., Kindler, A., Banzhaf, E., Ebert, A., and ReyesPaecke, S.: Indicators for sustainable land use management in Santiago de Chile, Ecol. Indic., 11, 1074-1083, doi:10.1016/j.ecolind.2010.12.007, 2011.

Winter, M. and Lobley, M. (Eds): What is land for? The food, fuel and climate change debate, Earthscan, London, 2009.

Zelenović Vasiljevic, T., Srdjević, Z., Bajčetić , R., and Vojinović Miloradov, M.: GIS and the Analytic Hierarchy Process for Regional Landfill Site Selection in Transitional Countries: A Case Study From Serbia, Environ. Manage., 49, 445-458, doi:10.1007/s00267-011-9792-3, 2009. 